\title{
Long-term Regulation of Neuronal Calcium Currents by Prolonged Changes of Membrane Potential
}

\author{
James L. Franklin, ${ }^{1, a}$ David J. Fickbohm, ${ }^{2}$ and Alan L. Willard ${ }^{1,2}$ \\ ${ }^{1}$ Department of Physiology and ${ }^{2}$ Curriculum in Neurobiology, University of North Carolina, Chapel Hill, North Carolina \\ 27599-7545
}

\begin{abstract}
Although rapid-onset, short-term regulation of neuronal $\mathrm{Ca}$ currents by neurotransmitters and second messengers is well documented, little is known about conditions that can cause longer-lasting changes in $\mathrm{Ca}$ channel function. We report here that persistent depolarization is accompanied by slowly developing long-term reduction of neuronal $\mathrm{Ca}$ currents. Rat myenteric neurons grown in cell culture for 1$7 \mathrm{~d}$ were studied with the tight-seal whole-cell recording technique. Macroscopic Ca-channel currents had decaying and sustained components at all days studied. When the neurons were grown in medium containing $25 \mathrm{~mm} \mathrm{KCl}$, which depolarized them to $-\mathbf{4 0} \mathrm{mV}$ and caused significant elevation of intracellular $\mathrm{Ca}$, the densities of both components of Ca-channel current decreased by $40-80 \%$. Several results suggest that different mechanisms underlie the downregulation of the two components. (1) The density of the decaying component decreased approximately four times faster than did that of the sustained component. (2) When neurons were returned to control medium, which contained $5 \mathrm{mM} \mathrm{KCl}$, the density of the sustained component returned to control levels within $24 \mathrm{hr}$, while that of the decaying component did not recover significantly. (3) Inhibitors of RNA and protein synthesis reduced or prevented downregulation of the sustained but not of the decaying component. (4) The dihydropyridine antagonist nitrendipine, which prevented the sustained elevation of intracellular $\mathrm{Ca}$ in neurons grown in $25 \mathrm{~mm} \mathrm{KCl}$, prevented downregulation of the sustained component but had no effect on downregulation of the decaying component. We suggest that these forms of regulation of Ca current density could help neurons adapt to altered levels of electrical activity and may contribute to changes in synaptic strength that occur during periods of increased or decreased electrical activity.
\end{abstract}

Regulation of neuronal Ca channels is extremely important because entry of $\mathrm{Ca}$ through voltage-gated channels is a major mechanism by which changes in membrane potential can influ-

Received Aug. 26, 1991; revised Nov. 26, 1991; accepted Dec. 5, 1991.

We thank Ms. P. Fleck for preparing cultures. Dr. L. Marshall and Dr. G. Oxford provided helpful criticisms of an earlier version of the manuscript. This work was supported by NIH Grants NS24362 and NS14899 to A.L.W. Partial tuition support for J.L.F. was kindly provided by Glaxo Pharmaceuticals.

Correspondence should be addressed to Dr. Alan L. Willard, Department of Physiology, CB \#7545, University of North Carolina, Chapel Hill, NC 275997545 .

- Present address: Department of Molecular Biology and Pharmacology, Washington University School of Medicine, 660 South Euclid, St. Louis, MO 63110.

Copyright (C) 1992 Society for Neuroscience $0270-6474 / 92 / 121726-10 \$ 05.00 / 0$ ence cellular processes. In addition to being an important determinant of the electrophysiological characteristics of many cells, voltage-gated Ca influx can trigger such important cellular events as neurotransmitter release, activation or inactivation of ionic channels, activation of protein kinases (Kaczmarek and Levitan, 1987), and activation of "immediate early genes" such as c-fos and c-jun (Sheng and Greenberg, 1990). Although it is clear that neurotransmitters (Dunlap and Fischbach, 1981; Wanke et al., 1987; Tsien et al., 1988; Lipscombe et al., 1989) and second messengers (DeRiemer et al., 1985; Rane and Dunlap, 1986; Gross and MacDonald, 1989) can rapidly and reversibly inhibit or enhance neuronal $\mathrm{Ca}$ currents, very little is now known about conditions that cause longer-lasting changes in Ca-channel function such as those that are observed during development (Yaari et al., 1987; O'Dowd et al., 1988; Nerbonne and Gurney, 1989). The development of Ca currents in cultured cells can be influenced by growth factors (Garber et al., 1989; Boland and Dingledine, 1990) or chronic depolarization (DeLorme et al., 1988). Ca currents also undergo long-term upor downregulation during prolonged exposure to dihydropyridines (Panza et al., 1985; Skattebol et al., 1989; Ferrante and Triggle, 1990). In this article, we report (1) that chronic depolarization causes long-term decreases in the density of macroscopic Ca currents in rat myenteric neurons and (2) that the densities of two kinetically separable components of the $\mathrm{Ca}$ currents in these neurons appear to be controlled by different regulatory mechanisms.

Some of these results have been reported in abstracts (Franklin and Willard, 1988, 1989).

\section{Materials and Methods \\ Cell cultures \\ Myenteric neurons were dissociated from small intestines of 3-d-old Sprague-Dawley rat pups and grown in cell culture as described pre- viously (Nishi and Willard, 1985; Willard, 1990). Neurons to be used for electrophysiological experiments were grown in $35 \mathrm{~mm}$ plastic tissue culture dishes that had been collagen coated. Those to be used for measurements of intracellular $\mathrm{Ca}$ concentration were grown on collagen- coated glass coverslips. The growth medium consisted of Eagle's Min- imum Essential Medium (MEM) supplemented with 5\%(v/v) rat serum, penicillin $\mathrm{G}(100 \mathrm{IU} / \mathrm{ml})$, streptomycin $(100 \mu \mathrm{g} / \mathrm{ml})$, and, when chron- ically depolarizing neurons, sufficient $\mathrm{KCl}$ to raise the final concentration to $25 \mathrm{~mm}$.}

\section{Electrophysiology}

Prior to plating, a specially constructed lathe was used to score a deep circle into the outside bottoms of the $35 \mathrm{~mm}$ dishes. This permitted a circular plastic slide containing the neurons to be removed easily at a later time by cutting through the scoring with a scalpel. These slides were sealed to the bottom of a circular Plexiglas chamber using dental 
wax. The volume of the chamber was approximately $0.5 \mathrm{ml}$. Solutions were added and removed via tubing inserted in ports and connected to a peristaltic pump or to syringes. After cultures had been placed in the chamber, they were rinsed several times with an external solution that consisted of Hanks' Balanced Salt Solution (137 mM NaCl, $5.4 \mathrm{~mm} \mathrm{KCl}$, $0.44 \mathrm{mM} \mathrm{KH} \mathrm{PO}_{4}, 0.34 \mathrm{mM} \mathrm{Na} \mathrm{HPO}_{4}$ ) supplemented with $2.5 \mathrm{~mm}$ $\mathrm{CaCl}_{2}, 10 \mathrm{~mm}$ glucose, and $5 \mathrm{~mm}$ HEPES-Na-HEPES (pH 7.35). Neurons were viewed with an inverted microscope with Hoffman modulation contrast optics. The tight-seal whole-cell recording technique (Hamill et al., 1981) was used for both current-clamp and voltage-clamp experiments. Patch pipettes were made from $1.5 \mathrm{~mm}$ Kimax-51 glass capillary tubing (Fisher). Their tips were polished to diameters that gave resistances of $1-2 \mathrm{M} \Omega$ when filled with recording solutions. Such electrodes typically formed 2-5 G $\Omega$ seals with myenteric neuronal membranes.

A Dagan 8900 patch-clamp amplifier whose head stage had a 100 $\mathrm{M} \Omega$ feedback resistor was used for both current-clamp and voltageclamp experiments. Calcium currents were sampled at $666 \mathrm{~Hz}$ and filtered at $1 \mathrm{kHz}$. Voltage protocols were controlled by an IBM AT computer connected to the amplifier via a DMA interface (LabMaster TL-1-40, Axon Instruments). The pCLaMp software package (versions 5 and 5.5, Axon Instruments) was used for data acquisition and analysis. Capacitative transients due to the electrode were compensated electronically. Series resistance could usually be kept below $5 \mathrm{M} \Omega$ by maintaining slight negative pressure on the back of the pipette. Electronic compensation of series resistance was not used. Data obtained from cells with large series resistances were not used.

Cultures were kept in the external solution described above until the whole-cell mode had been achieved, after which this solution was replaced with a recording solution containing $120 \mathrm{~mm}$ tetraethylammonium chloride, $20 \mathrm{~mm} \mathrm{BaCl}, 16 \mathrm{~mm}$ glucose, $3 \mu \mathrm{M}$ TTX, and $5 \mathrm{~mm}$ HEPES-Na-HEPES (pH 7.35). Barium replaced $\mathrm{Ca}$ as charge carrier in the recording solution to increase the amplitudes of currents carried through $\mathrm{Ca}$ channels (referred to hereafter as $\mathrm{Ca}$-channel currents) and to help block potassium currents. Pipette solution contained $150 \mathrm{~mm}$ $\mathrm{CsCl}, 2 \mathrm{~mm} \mathrm{MgCl}$, $1 \mathrm{~mm} \mathrm{Mg}$-ATP, $1 \mathrm{~mm}$ EGTA- $\mathrm{NaOH}$, and $5 \mathrm{~mm}$ HEPES-Na-HEPES (pH 7.35). All solutions used for electrophysiological experiments contained $28 \mu \mathrm{m}$ phenol red for $\mathrm{pH}$ indication.

Because the neurons did not tolerate the Ba-containing solutions very well, it was necessary to collect data in the shortest time that would permit sufficient intracellular dialysis to block potassium currents. To standardize the dialysis time and the number of pulses delivered, all data used for comparisons of Ca-channel current density were obtained in the following manner. Exactly 5 and $5.5 \mathrm{~min}$ after achieving the whole-cell mode, currents were evoked by delivering voltage steps to 0 $\mathrm{mV}$ from a holding potential of $-90 \mathrm{mV}$. Our criteria for adequate voltage control included rapid return of tail currents to baseline $(<4.5$ msec following repolarization) and the absence of "spiking" or "notching" of currents. Surprisingly, voltage control was often quite good even in cells having rather long processes. This may be due to localization of most Ca channels to the neuronal soma. In approximately $40 \%$ of neurons, the currents evoked by the first pulse were not well space clamped, but those evoked by the second and subsequent pulses did appear to be well clamped. Accordingly, all comparisons of current density were made on the currents evoked by the pulses at 5.5 min. Data were not used if the currents evoked at $5.5 \mathrm{~min}$ were not well clamped. (However, even when poorly clamped, chronically depolarized neurons had noticeably smaller Ca currents.) To correct for leak, the linear currents elicited by $20 \mathrm{mV}$ hyperpolarizing steps were scalcd appropriately and then subtracted from the currents evoked by the step to $0 \mathrm{mV}$.

As illustrated in Figure 1, Ca-channel currents were divided into two kinetic components by using a Marquardt-Levenberg nonlinear leastsquares minimization routine (PEAKFIT, version 2.0, Jandel Scientific) to determine the best fit of the sum of two exponentially decaying components to leak-subtracted records. Current densities were calculated by dividing the amplitudes of peak currents, or of the separate decaying and sustained components, by membrane capacitance, which was estimated by integrating the capacitative transients elicited by 20 $\mathrm{mV}$ hyperpolarizing steps from a holding potential of $-90 \mathrm{mV}$. Capacitative transients were sampled at $20 \mathrm{kHz}$ and filtered at $10 \mathrm{kHz}$.

For experiments measuring $\mathrm{Na}$ and $\mathrm{K}$ currents, the pipctte solution contained $150 \mathrm{~mm} \mathrm{KCl}$ instead of $150 \mathrm{~mm} \mathrm{CsCl}$. Amplitudes of $\mathrm{Na}$ currents were estimated by subtracting currents evoked in $3 \mu \mathrm{M}$ TTX from those evoked in the standard external solution. The $\mathrm{Na}$ currents

\section{Control (5K)}

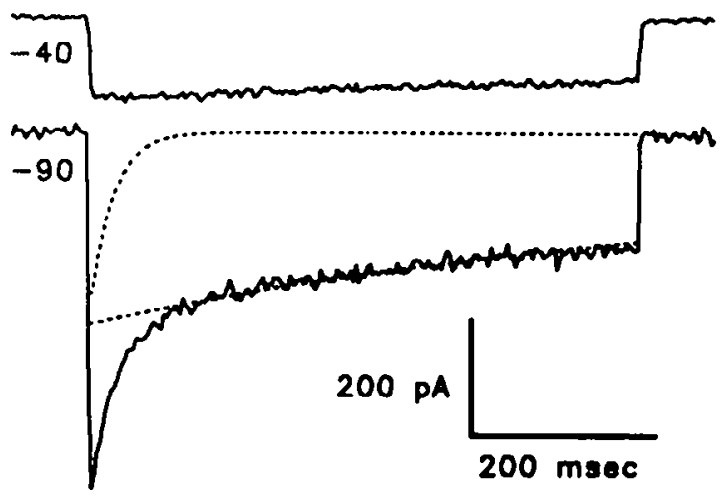

\section{Depolarized (25K)}

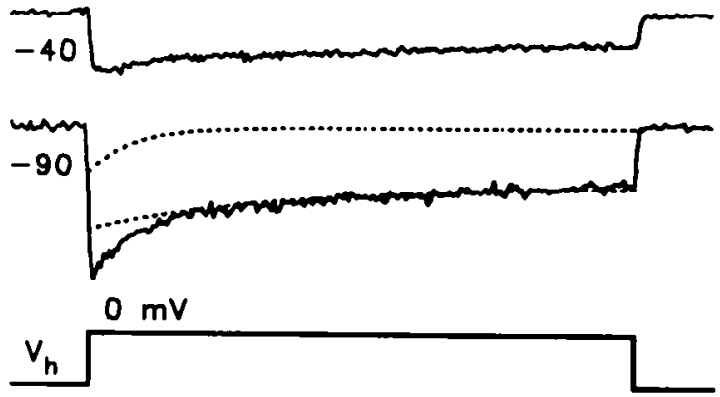

Figure 1. Ca-channel currents of myenteric neurons have multiple kinetic components. The solid lines are leak-subtracted records of $\mathrm{Ca}$ channcl currents recorded from two myenteric neurons. The control neuron had been grown $4 \mathrm{~d}$ in culture medium containing $5 \mathrm{~mm} \mathrm{KCl}$ $(5 K)$. The depolarized neuron had been grown $4 \mathrm{~d}$ in medium containing $25 \mathrm{~mm} \mathrm{KCl}(25 K)$. Currents elicited by voltage steps to $0 \mathrm{mV}$ from a holding potential $\left(V_{h}\right)$ of $-90 \mathrm{mV}$ had rapidly and slowly decaying components. Such currents were well fitted by the sum of two exponentially decaying components, which are plotted separately as broken lines. In contrast, currents evoked from a $V_{n}$ of $-40 \mathrm{mV}$ were well fitted with single slowly decaying exponentials (not shown).

were evoked by steps to $0 \mathrm{mV}$ from a holding potential of $-90 \mathrm{mV}$. Potassium currents were evoked in external solution containing $3 \mu \mathrm{M}$ TTX. Amplitudes of rapidly inactivating (A-type) $K$ currents were estimated by determining the difference between the peak outward currents evoked by steps to $+20 \mathrm{mV}$ from holding potentials of -60 and $-90 \mathrm{mV}$. Amplitudes of delayed-rectifier $\mathrm{K}$ currents evoked by steps to $+20 \mathrm{mV}$ from a holding potential of $-90 \mathrm{mV}$ were measured 500 msec after beginning the test pulse, by which time A-type $K$ currents had completely inactivated.

Similarly sized neurons were chosen for all experiments. Mean ( \pm SEM) capacitances for neurons grown in control medium containing $5 \mathrm{mM}$ $\mathrm{KCl}$ ( $5 \mathrm{~K}$ medium) and for those grown in depolarizing medium containing $25 \mathrm{mM} \mathrm{KCl}(25 \mathrm{~K}$ medium) were $12.5 \pm 1.0 \mathrm{pF}$ and $11.8 \pm 0.5$ $\mathrm{pF}$, respectively. Experiments were done at room temperature $\left(22-25^{\circ} \mathrm{C}\right)$.

\section{Calcium measurement}

Neurons were loaded with indicator dye by incubating cultures for 30 $75 \mathrm{~min}$ at $37^{\circ} \mathrm{C}$ in MEM containing the acetomethoxy esters of indo- 1 or fura-2 (3 $\mu_{\mathrm{M}}$ in $0.3 \%$ dimethyl sulfoxide; Molecular Probes; Grynkiewicz ct al., 1985). Inclusion of $200 \mu \mathrm{g} / \mathrm{ml}$ of pluronic F127 (Molecular Probes) in the incubation medium improved loading significantly. After loading, the cultures were rinsed several times with the external solution described above and incubated for up to $2 \mathrm{hr}$ to allow hydrolysis of the esters. Cultures were then placed on the stage of an inverted microscope and viewed through a $40 \times$ oil-immersion objective (CF Fluor, 1.30 
Table 1. Elevated $|\mathrm{Ca}|_{\text {i }}$ in chronically depolarized myenteric neurons

\begin{tabular}{lclll} 
Indicator & $\begin{array}{l}\text { Culture } \\
\text { condition }\end{array}$ & Ratio $^{\circ}$ & $\begin{array}{l}\text { Estimated } \\
{[\mathrm{Ca}]_{\mathrm{i}}(\mathrm{nM})^{\circ}}\end{array}$ & \multicolumn{1}{l}{$n$} \\
\hline Indo-1 & $5 \mathrm{~K}$ & $0.229 \pm 0.003$ & $196 \pm 5$ & 96 \\
& $25 \mathrm{~K}$ & $0.324 \pm 0.005$ & $337 \pm 9$ & 112 \\
Fura-2 & $5 \mathrm{~K}$ & $2.56 \pm 0.05$ & $126 \pm 9$ & 101 \\
& $25 \mathrm{~K}$ & $3.08 \pm 0.06$ & $185 \pm 11$ & 107
\end{tabular}

Cultures were grown $3-6 \mathrm{~d}$ in either $5 \mathrm{~K}$ or $25 \mathrm{~K}$ medium. Because similar values were found on cach day, data from cells in cultures of different ages have been combined. Although indo- 1 and fura- 2 gave different estimates of the absolute value of $[\mathrm{Ca}]$, neurons grown in $25 \mathrm{~K}$ medium always had significantly $(p<0.001)$ higher [Ca], than did neurons grown in $5 \mathrm{~K}$ medium.

- For indo-1, the ratio column indicates the ratio of the intensities of light emitted at 405 and $485 \mathrm{~nm}$ in response to illumination at $340 \mathrm{~nm}$; for fura-2, it indicates the ratio of the intensities of light emitted at $505 \mathrm{~nm}$ in response to illumination at 340 and $380 \mathrm{~nm}$.

- As discussed in Materials and Methods, these estimates of [Ca], are likely to be higher than the true absolute values of [Ca], and are presented only for purposes of comparison

NA). Measurements were made at room temperature $\left(22-25^{\circ} \mathrm{C}\right)$. All solutions used for estimation of $\mathrm{Ca}$ levels in chronically depolarized neurons contained $25 \mathrm{~mm} \mathrm{KCl}$.

Indo- I. A $75 \mathrm{~W}$ xenon arc lamp provided excitation at $340 \mathrm{~nm}$. To reduce bleaching of stained cells, a neutral density filter (ND8) was used and excitation was restricted to 100 -msec-long periods of means of a computer-controlled shutter located between the lamp housing and the microscope. Light emitted from selected cells was passed through a 400 $\mathrm{nm}$ high-pass filter. The emitted light was restricted to that from single cells or clusters of cells by means of an adjustable pinhole in the light path. A $440 \mathrm{~nm}$ dichroic mirror split the emitted light into two beams that were then passed through 405 and $485 \mathrm{~nm}$ bandpass filters to a pair of Nikon PI photometers. The outputs of the photometers were digitized by the LabMaster interface and collected by the CLAMPEX program (version 5.5), which was also used to control the shutter. Measurements were performed once per second. For estimation of resting levels of $\mathrm{Ca}$, the mean of 10 consecutive measurements was calculated. For estimation of changes in Ca levels in response to altered extracellular potassium, running averages of nine consecutive measurements were calculated. Such averaging significantly reduced the effects of noise in the photometer outputs, but also showed the apparent rates of change in Ca levels. Digitized records of the photometer outputs were saved as ASCI files and imported into LOTUS 123 for calculation of the ratios of the intensities of light emitted at 405 and $485 \mathrm{~nm}$ and for conversion of the ratios into estimated concentrations of $\mathrm{Ca}$.

Fura-2. The Nikon Photoscan 2 system was used for $\mathrm{Ca}$ measurements with fura-2. A $75 \mathrm{~W}$ xenon lamp and a computer-controlled optical chopper provided alternating excitation at 340 and $380 \mathrm{~nm}$. A photomultiplier tube, operating in single photon counting mode, was used to measure light emitted at $505 \mathrm{~nm}$. Software provided with the Photoscan system was used to calculate ratios of the intensity of light emitted in response to excitation at 340 and $380 \mathrm{~nm}$ and to convert the ratios into estimated concentrations of $\mathrm{Ca}$.

Calibration. In order to use Equation 5 of Grynkiewicz et al. (1985) to convert measured ratios to estimated $\mathrm{Ca}$ concentrations, several paramcters must be determined: $R_{\min }$, the minimum ratio in the absence of $\mathrm{Ca}: R_{\max }$, the maximim ratio at saturating concentrations of $\mathrm{Ca} ; F_{0}$, the fluorescence intensity mcasured in the absence of $\mathrm{Ca}$ at $485 \mathrm{~nm}$ for indo- 1 or in response to excitation at $380 \mathrm{~nm}$ for fura- $2 ; F_{s}$, the fluorescence intensity measured in the presence of saturating concentrations of $\mathrm{Ca}$ at $485 \mathrm{~nm}$ for indo- 1 or in response to excitation at $380 \mathrm{~nm}$ for fura-2; and $K_{D}$, the dissociation constant of the binding of $\mathrm{Ca}^{2+}$ to the indicator. Published values of 250 and $224 \mathrm{~nm}$ were used for the respective $K_{n}$ values of indo-1 and fura-2 (Grynkiewicz et al., 1985).

We initially tested several "in situ" methods for measuring the other parameters. These included incubating dye-loaded neurons or dye-loaded, ATP-depleted neurons in solutions of $\mathrm{Ca}$ ionophore (ionomycin) and known concentrations of free $\mathrm{Ca}$ (Wahl et al., 1990). However, we found considerable variability from cell to cell, especially for $R_{\max }$, apparently due to dye lcakage. Accordingly, we chose to use the following method for measuring $R_{\min }, R_{\max }$, and $F_{\mathrm{o}} / F_{s}$. A "standard curve" was constructed by plotting ratios as a function of known concentrations of free $\mathrm{Ca}$ in standard solutions that contained $150 \mathrm{~mm} \mathrm{KCl}, 1 \mathrm{~mm}$ EGTA, $10 \mathrm{~mm}$ HEPES-Na-HEPES (pH 7.4), $50 \mu \mathrm{m}$ indo-1 or fura-2 (pentapotassium salts), and variable amounts of $\mathrm{CaCl}_{2}$. The program EQCAL (Biosoft) was used to calculate the amounts of $\mathrm{CaCl}_{2}$ to add to obtain free Ca concentrations ranging from $0 \mathrm{nM}$ to $40 \mu \mathrm{M}$. Equation 5 of Grynkiewicz et al. (1985) was fitted to the standard curves by the program SIGMAPLOT (versions 4.0 and 4.1 , Jandel Scientific) and $R_{\min }, R_{\max }$, and a lumped constant $\left(K_{n}{ }^{*} F_{n} / F_{\mathrm{v}}\right)$ were calculated. The parameters derived from these calculations were then used to convert measured ratios to estimated $\mathrm{Ca}$ concentrations. For indo- 1 , mean ( $\pm \mathrm{SEM}$ ) values of $R_{\min }, R_{\max }$, and $K_{n} * F_{d} / F_{\text {s }}$ were $0.026 \pm 0.004,0.868 \pm 0.016$, and 604 \pm 24 , respectively. For fura-2, mean values for $R_{\min }, R_{\max }$, and $K_{D} * F_{0}$ $F$, were $1.28 \pm 0.06,30 \pm 3$, and $2184 \pm 29$, respectively. It is important to note that this method of calibration tends to overestimate the absolute value of [Ca], especially when using indo-l (Owen and Shuler, 1989; Wahl et al., 1990). This probably accounts for the result that indo-1 gave significantly higher estimates of [Ca], than did fura-2 (Table 1). We emphasize strongly that the purpose of these experiments was not to determine the true absolute value of [Ca], but rather to learn whether control and chronically depolarized cells differed from one another. Accordingly, all values of [Ca], should be considered to be estimatcs presented for purposes of comparison only.

\section{Drugs}

Concentrated stocks of transcriptional and translational inhibitors and nitrendipine were made in $100 \%$ ethanol. After addition of the inhibitors to the culture medium, ethanol concentrations ranged from $0.1 \%$ to $0.5 \%(v / v)$. In control experiments, application of $0.5 \%$ ethanol for 24 hr did not affect $\mathrm{Ca}$-channel currents. All chemicals were purchased from Sigma unless otherwise indicated.

\section{Statistical analysis}

All means are presented \pm SEM. The significance of differences was determined by means of two-tailed $t$ tests or Mann-Whitney $U$ tests. Differences were considered to be significant when $p<0.05$.

\section{Results}

\section{Effects of $25 \mathrm{~mm} \mathrm{KCl}$ on resting membrane potentials}

$25 \mathrm{~K}$ medium caused myenteric neurons to depolarize to a mean resting membrane potential of $-39 \pm 2 \mathrm{mV}(n=25)$ within 10 sec. The neurons did not repolarize significantly even when kept in $25 \mathrm{~K}$ medium for up to 6 weeks. When switched from $25 \mathrm{~K}$ medium to control $5 \mathrm{~K}$ medium, they repolarized within 10-30 sec to resting potentials indistinguishable from those of neurons in sibling cultures that had been grown in $5 \mathrm{~K}$ medium. It was striking that although the range of resting potentials recorded in $25 \mathrm{~K}$ medium was rather narrow $(-44$ to $-32 \mathrm{mV}$ ), the range of resting potentials recorded when these ncurons were switched to $5 \mathrm{~K}$ medium was as wide as that of neurons grown in $5 \mathrm{~K}$ medium ( -50 to $-80 \mathrm{mV}$ ). Thus, $25 \mathrm{~K}$ medium appears to "clamp" the resting potentials of myenteric neurons within a relatively restricted range. We believe that the observed variance in resting potentials in $5 \mathrm{~K}$ medium reflects true variability in the properties of the neurons and is not due simply to larger electrode leak artifacts that might arise from lower resting conductance at more hyperpolarized membrane potentials.

\section{Effects of chronic depolarization on Ca-channel currents}

As illustrated in Figure 1, myenteric Ca-channel currents can be subdivided into two components with different rates of inactivation (see also Hirning et al., 1990). A relatively rapidly inactivating ("decaying") component ( $\tau=45 \pm 6 \mathrm{msec}$ at a test potential of $0 \mathrm{mV}$ ) could be evoked only from holding potentials more negative than $-50 \mathrm{mV}$. In contrast, a relatively slowly decaying ("sustained") component ( $\tau=1820 \pm 208 \mathrm{msec}$ at 0 $\mathrm{mV}$ ) could be evoked from holding potentials up to $-10 \mathrm{mV}$. 


\section{Control}

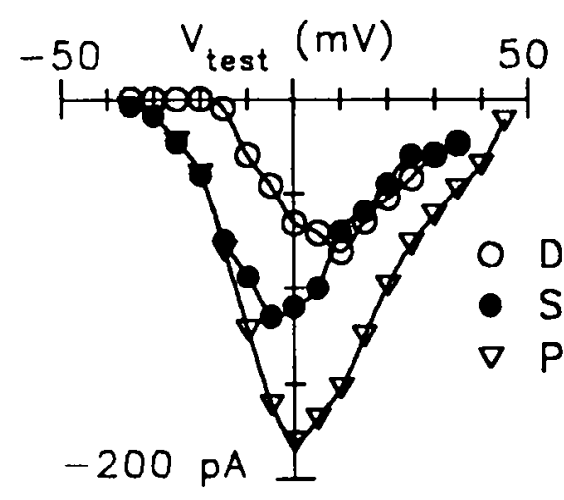

\section{Depolarized}

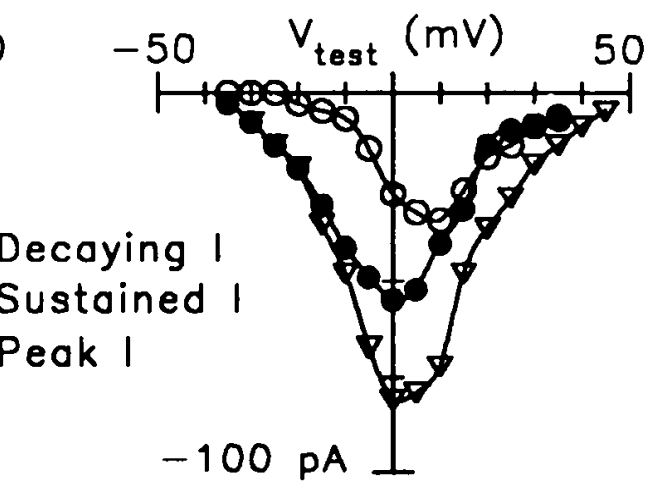

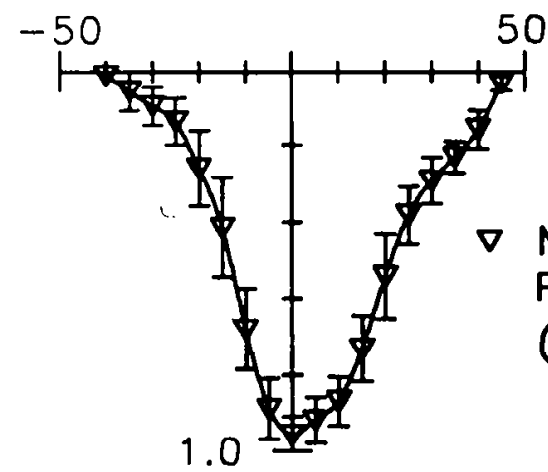
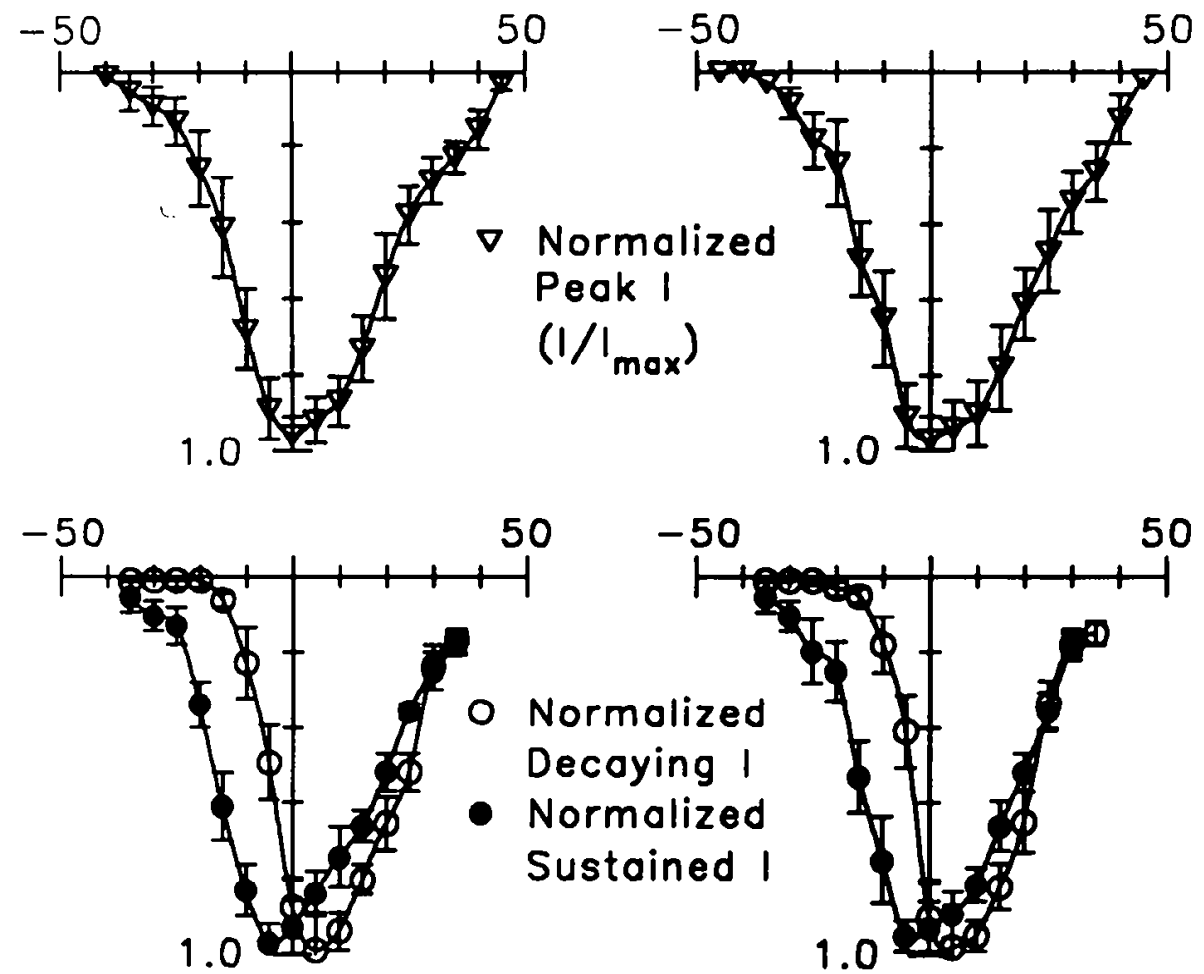

1.0

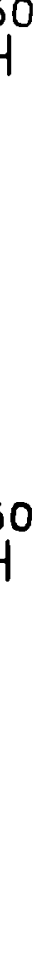

Figure 2. Chronic depolarization does not alter the current-voltage $(I / V)$ relations of Ca-channel currents. The left and right sides of the figure compare the $1 / V$ relations of Ca-channel currents from control and chronically depolarized neurons. Ca-channel currents werc evoked by steps to the indicated test potentials from a $V_{h}$ of $-90 \mathrm{mV}$. The top two panels show $I / V$ curves from single control and depolarized neurons. Contributions of decaying and sustained components to the peak currents were estimated by the curve-fitting procedure illustrated in Figure 1. The lower four panels show normalized $I / V$ curves for peak currents (middle) and for the decaying and sustained components (bottom). The points in the normalized $I / V$ curves are the means of data obtained from four control and from five depolarized neurons.
Figure 2 shows that the $I / V$ relations of the decaying and sustained components appeared identical in control and depolarized neurons. However, as shown in Figure 3, the densities of Ca-channel currents were significantly $(p<0.01)$ smaller in depolarized neurons on every day tested. Mean densities of the sustained and decaying components were reduced by $43-65 \%$ and by $53-78 \%$, respectively.

Figure 4 shows that densities of the two components declined at significantly different rates. Maximal reduction of the decaying component occurred $4-6 \mathrm{hr}$ after replacing $5 \mathrm{~K}$ medium with $25 \mathrm{~K}$ medium. In contrast, the density of the sustained component actually increased during the first $30 \mathrm{~min}$ after adding $25 \mathrm{~K}$ medium. It then decreased, reaching maximally suppressed levels after approximately $24 \mathrm{hr}$ of depolarization.

The reversibility of the suppression of the two components also differed significantly. When neurons were repolarized by switching them back to $5 \mathrm{~K}$ medium, the density of the sustained component returned to control levels within $24 \mathrm{hr}$, while that of the decaying component did not change significantly (Fig. 4).

The suppressant effects of chronic depolarization appeared to be specific for Ca currents. The development of the TTX-sensitive Na current was not studied in detail because it could be adequately voltage clamped only in very young cultures, but there was no significant difference in the mean amplitudes of TTX-sensitive currents evoked in neurons grown for $6 \mathrm{~d}$ in either $5 \mathrm{~K}(2147 \pm 213 \mathrm{pA} ; n=18)$ or $25 \mathrm{~K}$ medium $(2369 \pm$ $347 \mathrm{pA} ; n=10$ ). The density of the delayed-rectifier potassium current remained relatively constant at about $150 \mathrm{pA} / \mathrm{pF}$ on days 1,3 , and 7 in culture for neurons grown in either $5 \mathrm{~K}$ or $25 \mathrm{~K}$ medium. The only other significant electrophysiological difference we observed between control and chronically depolarized neurons was that, on days 1 and 3 in culture, chronically depolarized neurons had significantly higher densities of rapidly inactivating (A-type) potassium current. On days 1 and 3, con- 


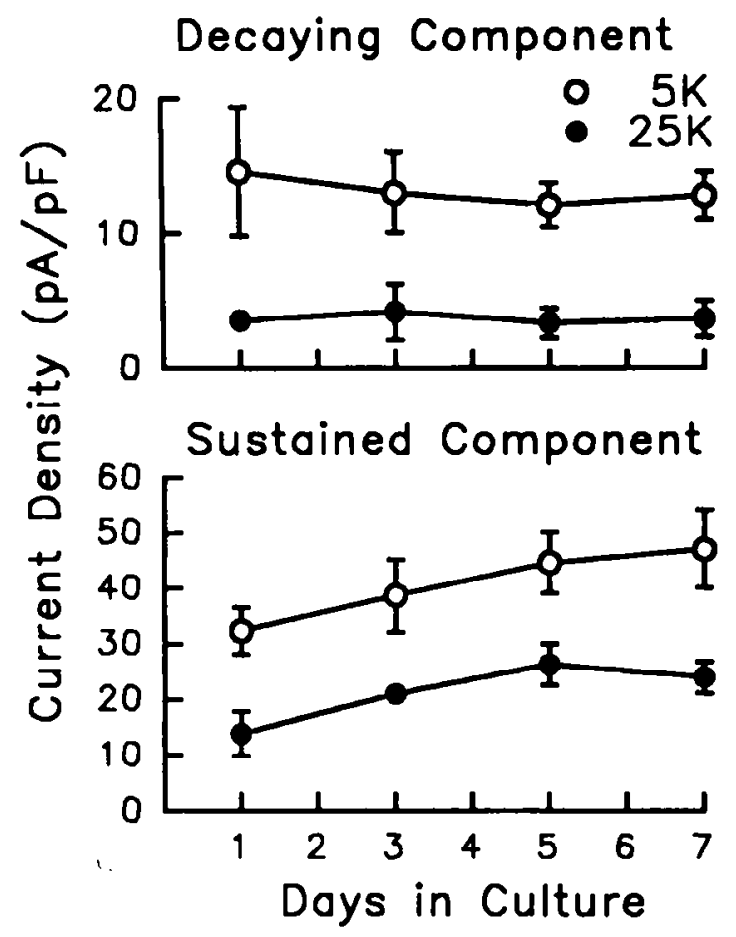

Figure 3. Decreased Ca-channel current density in chronically depolarized neurons. Neurons were grown $1-7 \mathrm{~d}$ in $5 \mathrm{~K}$ or $25 \mathrm{~K}$ medium. The densities of the decaying and sustained components of $\mathrm{Ca}$-channel current were significantly lower in chronically depolarized neurons at all days tested $(p<0.01) . N=9-15$ for all points

trol neurons had A-type $K$ current densities of $42 \pm 16$ and 93 $\pm 10 \mathrm{pA} / \mathrm{pF}$, respectively, while chronically depolarized neurons had densities of $107 \pm 21$ and $281 \pm 60 \mathrm{pA} / \mathrm{pF}$. By day 7 , the densities of A-type $\mathrm{K}$ currents of control and depolarized neurons, $108 \pm 24$ and $138 \pm 23 \mathrm{pA} / \mathrm{pF}$, respectively, were not significantly different ( $n=10$ on all days).

\section{Effect of chronic depolarization on intracellular $\mathrm{Ca}$ concentration}

To test whether chronic depolarization caused persistent changes in intracellular $\mathrm{Ca}$ levels $\left([\mathrm{Ca}]_{i}\right)$, we monitored [Ca $]_{i}$ before, during, and after adding $25 \mathrm{~K}$ medium to control cultures. Addition of $25 \mathrm{~K}$ medium caused [Ca], to increase rapidly, reaching a peak in about $10 \mathrm{sec}$ (Fig. 5). During the next $30 \mathrm{~min}$, [Ca], declined steadily, eventually stabilizing at new levels that were significantly elevated in comparison to control cells in $5 \mathrm{~K}$ medium (Table 1). Neurons grown in $25 \mathrm{~K}$ medium retained significantly elevated [Ca], for at least $7 \mathrm{~d}$. The elevation of $[\mathrm{Ca}]$ in neurons grown in $25 \mathrm{~K}$ medium was completely prevented by $5 \mu \mathrm{M}$ nitrendipine, a dihydropoyridine that antagonizes sustained (Ltype) Ca currents in many cells (Bean, 1989a), including myenteric neurons (Hirning et al., 1990). When neurons in $25 \mathrm{~K}$ medium were switched to $5 \mathrm{~K}$ medium, $[\mathrm{Ca}]_{i}$ quickly dropped to levels comparable to those in control neurons grown in $5 \mathrm{~K}$ medium (Fig. 5).

\section{Role of $\mathrm{Ca}$ influx in suppression of calcium currents}

Although Ca-dependent inactivation of neuronal Ca currents is a well-documented phenomenon (Eckert and Tillotson, 1981; Morad et al., 1988; Gutnick et al., 1989), it seems unlikely to be the major cause of decreased Ca-current density in chroni-

\section{SUPPRESSION}
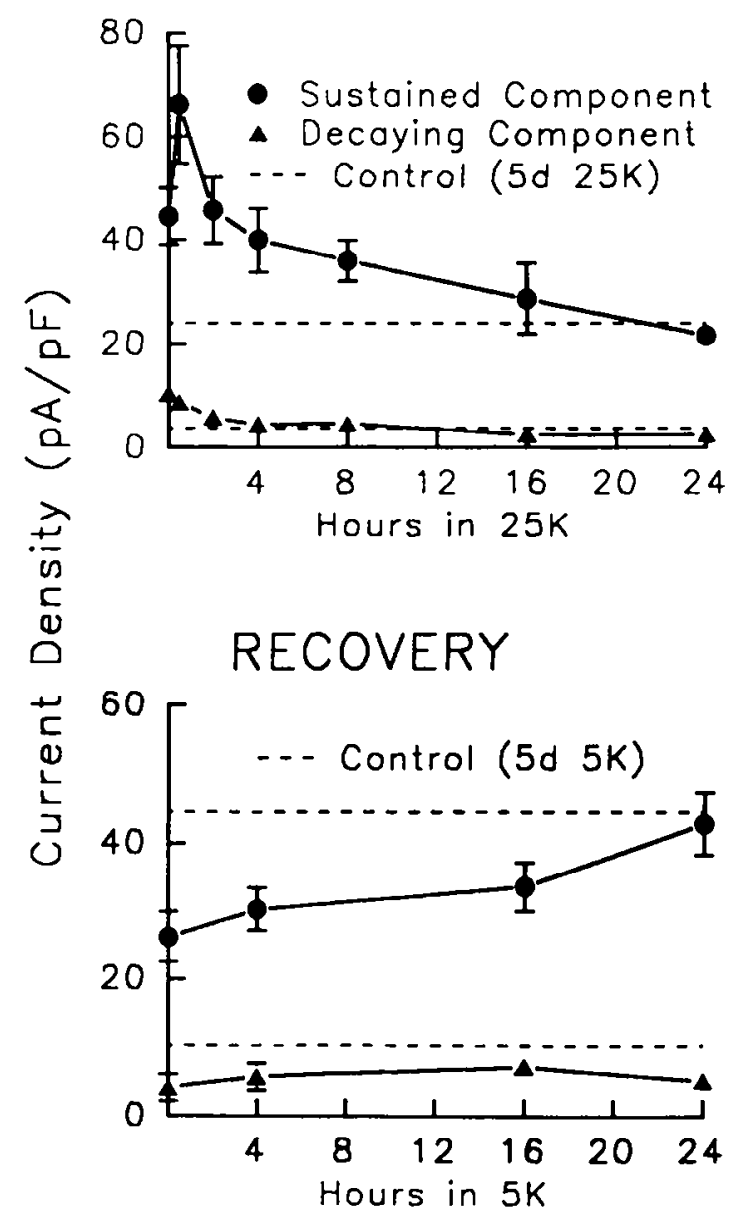

Figure 4. Depolarization suppresses sustained and decaying components of Ca-channel current at different rates and with different degrees of reversibility. The abscissae indicate the number of hours cells were exposed to $25 \mathrm{~K}$ (top) or $5 \mathrm{~K}$ (bottom) medium before current density measurements were made on day 5 . Thus, $4 \mathrm{hr}$ means that a cell was grown in $5 \mathrm{~K}$ or $25 \mathrm{~K}$ medium for $4 \mathrm{~d}$ and $20 \mathrm{hr}$ and then switched to the other medium for $4 \mathrm{hr}$ prior to the electrophysiological assay. $S U P$ PRESSION, Current densities of neurons grown in $5 \mathrm{~K}$ medium and then switched to $25 \mathrm{~K}$ medium for the indicated number of hours before measuring current density on day 5 are compared to those of neurons grown $5 \mathrm{~d}$ in $25 \mathrm{~K}$ medium. RECOVERY. Neurons grown in $25 \mathrm{~K}$ medium were switched to $5 \mathrm{~K}$ medium for the indicated number of hours before measuring current densities on day 5 . Densities of the sustained component recovered to $96 \%$ of control levels within $24 \mathrm{hr}$. In contrast, densities of the rapidly decaying component did not change significantly during this same period. $N=9-14$ for all data points.

cally depolarized myenteric neurons for two reasons. First, the densities of the two components of Ca-channel current declined very slowly compared to the time course of elevation of $[\mathrm{Ca}]_{i}$ (compare Figs. 4 and 5). Second, the density of the sustained component actually increased significantly during the first 30 min of depolarization (Fig. 4), the period when $[\mathrm{Ca}]_{i}$ was highest. However, it is possible that elevated [Ca], triggers other mechanisms that cause reduced $\mathrm{Ca}$ current density. To test the hypothesis that $\mathrm{Ca}$ influx is a necessary step in the suppression of Ca currents by depolarization, we tested whether $5 \mu \mathrm{M}$ nitrendipine could prevent $25 \mathrm{~K}$ medium from reducing Ca-current density. The results of this experiment suggested that $\mathrm{Ca}$ influx 


\begin{tabular}{|c|c|c|c|}
\hline Medium & Drug & $\begin{array}{l}\text { Sustained } \\
\text { current density } \\
(\mathrm{pA} / \mathrm{pF})\end{array}$ & $\begin{array}{l}\% \text { Change } \\
\text { from } \\
5 \mathrm{~d} 25 \mathrm{~K} \\
\end{array}$ \\
\hline \multirow{4}{*}{$\begin{array}{l}4 \mathrm{~d} 25 \mathrm{~K}, 1 \mathrm{~d} 5 \mathrm{~K} \\
+ \text { drug }\end{array}$} & None & $43 \pm 3$ & 65 \\
\hline & $A C D$ & $29 \pm 4$ & 12 \\
\hline & DRB & $23 \pm 2$ & -3 \\
\hline & $\mathrm{CHX}$ & $28 \pm 2$ & 8 \\
\hline $5 \mathrm{~d} 25 \mathrm{~K}$ & None & $26 \pm 4$ & \\
\hline
\end{tabular}

Cultures were grown $4 \mathrm{~d}$ in $25 \mathrm{~K}$ medium and then switched for $24 \mathrm{hr}$ to normal $5 \mathrm{~K}$ medium or to $5 \mathrm{~K}$ medium containing one of the following drugs: ACD $(3.2$ $\mu \mathrm{M}), \mathrm{DRB}(50 \mu \mathrm{M}), \mathrm{CHX}(3.6 \mu \mathrm{M})$. In the absence of inhibitors, the density of the sustained component of $\mathrm{Ca}$-channel current recovered to control levels. In the presence of the inhibitors, sustained current density did not change significantly $(p>0.2)$ from that observed in cells grown $5 \mathrm{~d}$ in $25 \mathrm{~K}$ medium.

is not required for suppression of the decaying component but is required for suppression of the sustained component: $24 \mathrm{hr}$ aftr 4 -d-old cultures had been switched from $5 \mathrm{~K}$ medium to $25 \mathrm{~K}$ medium containing $5 \mu \mathrm{M}$ nitrendipine, the density of the decaying component $(4.1 \pm 0.5 \mathrm{pA} / \mathrm{pF})$ was reduced to the same extent as that of neurons grown in $25 \mathrm{~K}$ medium, while the density of the sustained component $(40 \pm 5 \mathrm{pA} / \mathrm{pF})$ was not significantly reduced.

The simplest interpretation of the effects of nitrendipine is that $\mathrm{Ca}$ influx is required for depolarization-induced suppression of the sustained component. However, there is a potential complication: in several cell types, dihydropyridines can cause upregulation of $\mathrm{Ca}$ channels (Skattebol et al., 1989; Ferrante and Triggle, 1990). Thus, it is possible that nitrendipine prevents suppression of the sustained component by a mechanism that is independent of its ability to prevent $\mathrm{Ca}$ influx. To test whether nitrendipine can cause upregulation of $\mathrm{Ca}$ channels in myenteric neurons, we measured current densities in neurons that had been grown for $24 \mathrm{hr}$ in $5 \mathrm{~K}$ medium containing $5 \mu \mathrm{M}$ nitrendipine. We found that this treatment caused the densities of the sustained and decaying components to increase by $66 \%$ to $74 \pm$ $10 \mathrm{pA} / \mathrm{pF}$ and by $60 \%$ to $16 \pm 2 \mathrm{pA} / \mathrm{pF}(n=8)$, respectively.

The ability of nitrendipine to cause upregulation of $\mathrm{Ca}$ currents in control neurons complicates the interpretation of its prevention of depolarization-induced suppression of the sustained Ca current because it is not known how dihydropyridines cause upregulation of $\mathrm{Ca}$ channels. However, the simplest way to explain the ability of dihydropyridines to cause upregulation of $\mathrm{Ca}$ channels and to prevent the effects of depolarization is to hypothesize that both effects result from a single mechanism: reduced influx of $\mathrm{Ca}$. If this hypothesis is correct, then dihydropyridines should cause reduced resting influx of $\mathrm{Ca}$ into cells growing in $5 \mathrm{~K}$ medium. To test this hypothesis, we measured [Ca], in neurons grown in $5 \mathrm{~K}$ medium after a $24 \mathrm{hr}$ exposure to $5 \mu \mathrm{M}$ nifedipine or $5 \mu \mathrm{M}$ nitrendipine. Both compounds caused a $10-15 \%$ reduction of [Ca]. Collins et al. (1991) have also reported that dihyropyridines cause a significant reduction of resting $[\mathrm{Ca}]_{i}$ in neurons in $5 \mathrm{~K}$ medium. Thus, it is possible that all effects of dihydropyridines on Ca channel density in myenteric neurons can be explained by a single mechanism. However, the possibility that dihydropyridines can also cause upregulation of Ca channels by other mechanisms should be explored further.

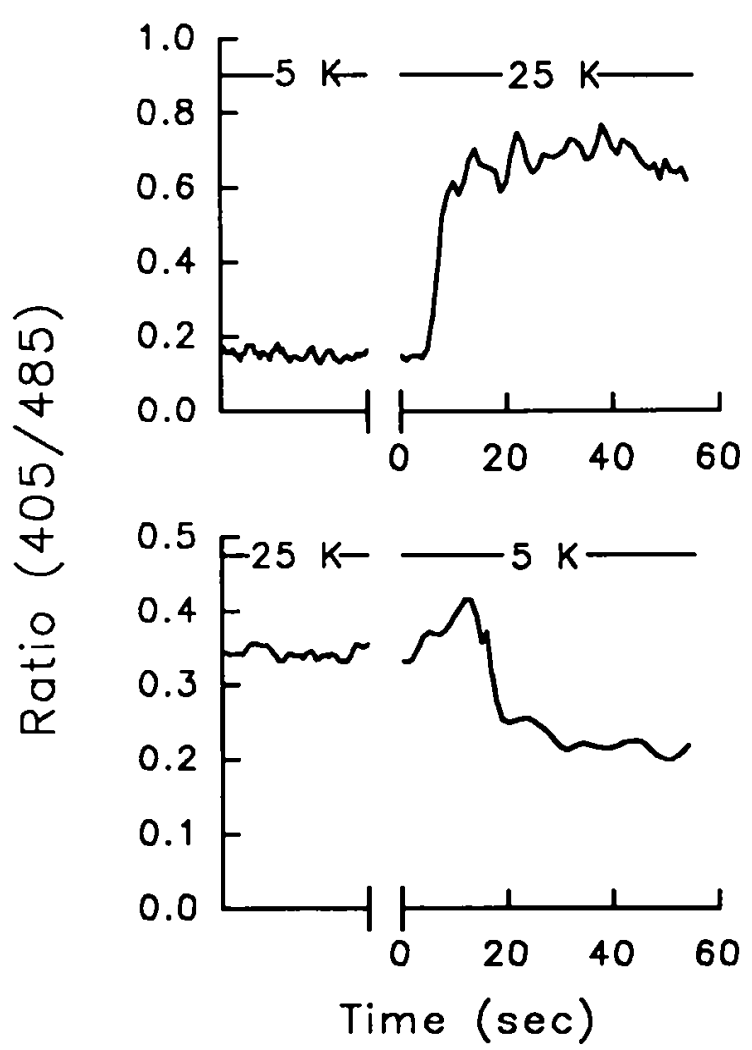

Figure 5. Rapid changes in intracellular Ca concentration in response to altered extracellular potassium. Top. Addition of $25 \mathrm{~K}$ medium to an indo-1-loaded neuron that had been grown in $5 \mathrm{~K}$ medium for $4 \mathrm{~d}$ caused [Ca], to increase rapidly to a level significantly higher than those found in either control or chronically depolarized neurons (Table 1). [Ca], decreased significantly during the next $5-60$ min of depolarization, eventually reaching new steady state levels comparable to those reported in Table 1 (not illustrated). Bottom. Addition of $5 \mathrm{~K}$ medium to a neuron grown $4 \mathrm{~d}$ in $25 \mathrm{~K}$ medium caused [Ca] ${ }_{i}$ to drop rapidly to a level comparable to those observed in control cells grown in $5 \mathrm{~K}$ medium (Table 1). The breaks in the records represent $10-15 \mathrm{sec}$ when solutions were changed. The data are presented as ratios rather than as absolute values of concentration because, as described in Materials and Methods, the calibration method used almost certainly overestimates the true values of $[\mathrm{Ca}]$.

\section{Effects of inhibitors of transcription and translation}

Effects on sustained current density. Previous studies of pheochromocytoma (PC12) cells have suggested that chronic depolarization causes a reduced number of functional sustained (Ltype) Ca channels in those cells (DeLorme and McGee, 1986; DeLorme et al., 1988). Because the observed rates of suppression and recovery of the sustained $\mathrm{Ca}$ current component of myenteric neurons are similar to those observed for the depolarization-induced decrease and repolarization-induced recovery of ${ }^{3} \mathrm{H}$-nitrendipine binding sites on $\mathrm{PCl} 2$ cells, we tested the hypothesis that depolarization causes loss of functional $\mathrm{Ca}$ channels in myenteric neurons. If this hypothesis is correct, then inhibition of macromolecular synthesis should prevent recovery upon repolarization because new channels would have to be made to replace lost ones. To test this prediction, myenteric neurons grown in $25 \mathrm{~K}$ medium were switched to $5 \mathrm{~K}$ medium containing inhibitors of RNA or protein synthesis. Table 2 shows that the transcriptional inhibitors 5,6-dichloro- 1 - $\beta$-ribobenzimidazole (DRB) (Tamm and Sehgal, 1978; Ribera and Spitzer, 
Table 3. Effects of inhibitors of macromolecular synthesis on Cachannel current density

\begin{tabular}{llll} 
& & \multicolumn{2}{l}{ Current component } \\
\cline { 3 - 4 } Medium & Drug & Sustained & Decaying \\
\cline { 3 - 4 } 4 d 5K, 1 d 5K + drug & None & $44 \pm 6$ & $10 \pm 2$ \\
& ACD & $44 \pm 7$ & $19 \pm 7^{*}$ \\
& DRB & $46 \pm 6$ & $9 \pm 2$ \\
& CHX & $54 \pm 7^{*}$ & $20 \pm 6^{*}$
\end{tabular}

Cultures were grown $4 \mathrm{~d}$ in $5 \mathrm{~K}$ medium and then switched for $24 \mathrm{hr}$ to $5 \mathrm{~K}$ medium containing ACD, DRB, or CHX. Ca-channel current densities were determined at the end of the $24 \mathrm{hr}$ exposure.

* Significantly different $(p<0.05)$ from control.

1989) and actinomycin D (ACD) (Reich and Goldberg, 1964; O'Dowd, 1983) and the translational inhibitor cycloheximide (CHX) (Wettstcin et al., 1964) reduced or blocked recovery of the sustained component.

Two hypotheses that could explain loss of $\mathrm{Ca}$ channels are (1) that depolarization triggers decreased synthesis or assembly of Ca channels and (2) that depolarization causes increased production of proteins that modify or degrade $\mathrm{Ca}$ channels. We have obtained data that are consistent with the second but not with the first hypothesis.

The hypothesis that depolarization triggers decreased synthesis or assembly of channels predicts that the channels that carry the sustained component of $\mathrm{Ca}$ current are relatively short lived and that inhibition of macromolecular synthesis should reduce current density of control neurons grown in $5 \mathrm{~K}$ medium. However, Table 3 shows that a $24 \mathrm{hr}$ exposure to these inhibitors did not reduce Ca-channel current density. Indeed, $\mathrm{CHX}$ actually caused sustained current density to increase. These data, which suggest that channel half-life under control conditions is significantly longer than the time course of suppression by depolarization, are inconsistent with the hypothesis that depolarization causes decreased production of short-lived channcls. In contrast, the data in Table 4 do support the hypothesis that depolarization causes increased production of proteins that modify or degrade Ca channels. Inhibitors of RNA or protein synthesis decreased the ability of $25 \mathrm{~K}$ medium to suppress sustained current density. Thus, depolarization appears to reduce the sustained component via a process that requires synthesis of new proteins, possibly ones that degrade or otherwise permanently modify channels.

Effects on decaying current density. Inhibitors of macromolecular synthesis had quite different effects on the density of the decaying component. As shown in Table 3, both ACD and CHX caused significant increases in the density of the decaying current component when added for $24 \mathrm{hr}$ to cultures that had been grown in $5 \mathrm{~K}$ medium for $4 \mathrm{~d}$. However, they did not interfere significantly with the ability of $25 \mathrm{~K}$ medium to suppress the density of the decaying current component (Table 4). Thus, it appears that depolarization causes downregulation of the decaying and sustained components of $\mathrm{Ca}$-channel current by different mechanisms.

\section{Discussion}

We have shown that culture conditions that depolarize myenteric neurons to $-40 \mathrm{mV}$ caused significant decreases in the density of macroscopic Ca-channel current. When the macroscopic currents were subdivided into decaying and sustained components on the basis of their rates of inactivation, the two components were found to differ significantly in the rate at which they were suppressed by depolarization, in their ability to recover when the neurons were repolarized, in the sensitivity of the downregulation to inhibitors of RNA and protein synthesis, and in the sensitivity of the downregulation to the dihydropyridine Ca-channel antagonist nitrendipine. When combined with previously reported differences in kinetics, voltage dependence, and pharmacological characteristics (Hirning et al., 1990), these data argue strongly that different species of $\mathrm{Ca}$ channels underlie the decaying and sustained components of macroscopic $\mathrm{Ca}$ channel currents in myenteric neurons. In the remainder of this section we will consider mechanisms by which depolarization might cause decreased $\mathrm{Ca}$-channel current density and the possible significance of this phenomenon.

\section{What underlies decreased current density?}

Decreased current density could result from reduced probability of channel opening at a given test potential (Bean, 1989b; Lipscombe et al., 1989), from decreased unitary channel conductance, or from fewer functional channels per unit area of membrane. We consider the last possibility to be the most likely because the $I / V$ relations of Ca-channel currents did not change in chronically depolarized neurons and because there is no precedent for unitary channel conductance decreasing while kinetics and $I / V$ relations remain unchanged.

Table 4. Inhibitors of macromolecular synthesis reduce depolarization-induced downregulation of sustained Ca-channel current density

\begin{tabular}{|c|c|c|c|c|c|}
\hline \multirow[b]{3}{*}{ Medium } & \multirow[b]{3}{*}{ Drug } & \multicolumn{4}{|c|}{ Current Component } \\
\hline & & \multicolumn{2}{|l|}{ Sustained } & \multicolumn{2}{|l|}{ Decaying } \\
\hline & & $\begin{array}{l}\text { Density } \\
(\mathrm{pA} / \mathrm{pF})\end{array}$ & $\begin{array}{l}\% \text { Sup- } \\
\text { pression }\end{array}$ & $\begin{array}{l}\text { Density } \\
\text { (pA/pF) }\end{array}$ & $\begin{array}{l}\text { \% Sup- } \\
\text { pression }\end{array}$ \\
\hline \multirow[t]{4}{*}{4 d $5 \mathrm{~K}, 1 \mathrm{~d} 25 \mathrm{~K}+$ drug } & None & $23 \pm 3$ & 48 & $3 \pm 2$ & 70 \\
\hline & $\mathrm{ACD}$ & $38 \pm 5$ & 14 & $6 \pm 2$ & 68 \\
\hline & DRB & $35 \pm 4$ & 24 & $4 \pm 1$ & 56 \\
\hline & $\mathrm{CHX}$ & $43 \pm 2$ & 20 & $8 \pm 2$ & 60 \\
\hline
\end{tabular}

Cultures were grown $4 \mathrm{~d}$ in $5 \mathrm{~K}$ medium and then switched for $24 \mathrm{hr}$ to normal $25 \mathrm{~K}$ medium or to $25 \mathrm{~K}$ medium containing ACD, DRB, or CHX. "\% Suppression" indicates the decrease in current density relative to that of the cells $(4 \mathrm{~d} 5 \mathrm{~K}$, 1 d $5 \mathrm{~K}+$ drug) in Table 3 . All three inhibitors significantly $(p<0.01)$ reduced the ability of $25 \mathrm{~K}$ medium to suppress the sustained component but had no significant effect $(p>0.2)$ on its ability to reduce the decaying component. 
Because all neurons in this study had similar capacitances, a decrease in functional channels per unit area of membrane must be due to a net loss of functional channels rather than to a net gain of membrane surface area. Loss of functional channels could be caused by any of the following: (1) decreased synthesis of channels, (2) prolonged Ca- or voltage-dependent inactivation of channels, (3) a prolonged decrease in phosphorylation of channels due to increased phosphatase activity or decreased kinase activity (see Armstrong, 1989), or (4) increased degradation of channels. Our data do not support the first two possibilities. The failure of inhibitors of RNA and protein synthesis to decrease Ca-channel current density in control neurons suggests that $\mathrm{Ca}$ channels in myenteric neurons are too long lived for decreased synthesis to be able to account for the rapidity with which depolarization causes decreased current density. Prolonged Ca-dependent inactivation is possible but seems unlikely because of the quite different time courses of depolarization-induced downregulation of Ca-channel currents and elevation of $[\mathrm{Ca}]_{i}$. In particular, the fact that the density of the sustained component actually incrcases during the first $30 \mathrm{~min}$ of depolarization, the time when [Ca $]_{i}$ is most elevated, argues against $\mathrm{Ca}$-dependent inactivation. Furthermore, $[\mathrm{Ca}]_{i}$ returns to control levels quite quickly after repolarization but $\mathrm{Ca}$-channel current density recovers slowly in the case of the sustained component and not at all in the case of the decaying component. We are unaware of any precedent for voltage-dependent inaclivation and recovery from it being sensitive to inhibitors of protein and RNA synthesis.

Further experiments will be necessary to determine whether either of the other two mechanisms we have considered-modification or degradation-can account for our results. However, we suggest that degradation may be a more likely mechanism that altered phosphorylation for the following reasons: (1) DeLorme et al. (1988) showed that prolonged depolarization of PC1 2 cells led to a loss of binding sites for ${ }^{3} \mathrm{H}$-nitrendipine. We are unaware of evidence that altered phosphorylation of $\mathrm{Ca}$ channels changes their ability to bind dihydropyridines (but see the review by Scott and Dolphin, 1989, of evidence that GTPbinding proteins can alter the ability of dihydropyridines to inhibit Ca currents). (2) Inhibitors of macromolecular synthesis prevented recovery of the sustained component when neurons were switched back to $5 \mathrm{~K}$ medium from $25 \mathrm{~K}$ medium. This suggests that new channels must be synthesized in order for recovery to occur. (3) Irreversible, enzymatically mediated rundown of $\mathrm{Ca}$ currents has been observed in neurons ( $\mathrm{Chad}$ and Eckert, 1986). A candidate protease for degrading Ca channels is calpain, a Ca-dependent endoprotease that can cause irreversible Ca-current "rundown" in guinea pig myocytes (Belles et al., 1988). Calpain has also been implicated in degradation of a variety of membrane proteins (Dice, 1987; Melloni and Pontremoli, 1989). Although there is no precedent for functionally irreversible phosphorylation of ion channels, phosphorylation of $\beta$-adrenergic receptors can trigger their internalization (Sibley et al., 1987). If such internalization was irreversible, this would be an example of phosphorylation triggering permanent removal of membrane proteins.

\section{What couples depolarization to loss of calcium?}

The most likely candidate for triggering a loss of $\mathrm{Ca}$ channels in response to prolonged depolarization is $\mathrm{Ca}$ itself, which links a wide variety of responses to electrical activity and to potassium depolarization. $[\mathrm{Ca}]_{i}$ increases rapidly when myenteric neurons
(Fig. 5 and Hirning et al., 1990) or PC12 cells (DeLorme et al., 1988) are first depolarized and it remains elevated in neurons grown in $25 \mathrm{~K}$ medium (Table 1). At least some of the initial rise of $[\mathrm{Ca}]_{i}$ cvoked by $25 \mathrm{~K}$ medium was probably causcd by influx through channels underlying both components of Ca current. However, the resting membrane potentials observed in $25 \mathrm{~K}$ medium $(-40 \mathrm{mV})$ cause nearly complete inactivation of the rapidly decaying component and approximately $50 \%$ inactivation of the sustained component. Thus voltage-dependent inactivation of $\mathrm{Ca}$ channels and such mechanisms as $\mathrm{Na} / \mathrm{Ca}$ exchange (Carafoli, 1987), intracellular buffering, and active pumping of $\mathrm{Ca}$ probably all help lower [Ca] $]_{i}$ to levels below those first elicited by depolarization.

The results of the experiments with nitrendipine suggest that influx of Ca through dihydropyridine-sensitive channels is necessary for the downregulation of the sustained, but not of the decaying, component of $\mathrm{Ca}$-channel current. However, the apparent ability of nitrendipine to prevent downregulation of the sustained current must be interpreted with caution because nitrendipine caused upregulation of $\mathrm{Ca}$ currents in control cultures. Other types of $\mathrm{Ca}$ channel blockers were not useful for addressing this question because they either were functionally irreversible (conotoxin), thereby precluding measurement of Cachannel currents, or were toxic (cadmium). DeLorme et al. (1988)

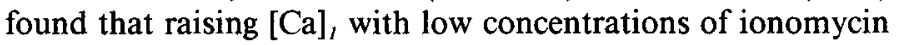
mimicked the ability of elevated $\mathrm{K}$ to decrease ${ }^{3} \mathrm{H}$-nitrendipine binding sites in PC1 2 cells. However, our attempts to raise $[\mathrm{Ca}]_{i}$ in control neurons with the Ca ionophore A23187 $(10 \mu \mathrm{M})$ caused massive cell death, even at external $\mathrm{Ca}$ concentrations as low as $1 \mu \mathrm{M}$. Thus, a definitive test of the role of $\mathrm{Ca}$ influx in the reduction of sustained Ca-channel current density by chronic depolarization of myenteric neurons awaits development of a means to alter $\mathrm{Ca}$ influx without irreversibly blocking the channels, causing upregulation of the channels, or killing the neurons.

\section{Possible significance}

Neurons in vivo almost certainly never experience depolarizations as prolonged as those caused by culturing cells in elevated potassium. Thus, it will be important to test whether more physiological electrical stimuli can also trigger downregulation of Ca channels. Walicke et al. (1977) found that sustained potassium depolarizations and briefer, more physiological electrical stimuli had similar effects on the neurotransmitter phenotypes of rat sympathetic neurons in culture.

If they can be triggered by altered electrical activity of neurons in vivo, long-term changes in Ca currents could serve a variety of functions. Decreased $\mathrm{Ca}$ entry during electrical activity could help protect chronically activated neurons against $\mathrm{Ca}$-mediated excitotoxicity. Long-term changes in neurotransmitter release resulting from alterations in Ca current density could signifcantly alter synaptic strength. To date, there have not been any in vivo studies of the effects of increased electrical activity on neuronal Ca-current densities. However, several studies have shown that prolonged decreases in electrical activity are accompanied by increased synaptic strength and that stimulation leads to decreased synaptic strength (Robbins and Fischbach, 1971; Gallego et al., 1979; Hinz and Wernig, 1988; Nguyen and Atwood, 1990). In the case of the crustacean neuromuscular junction, inhibition of protein synthesis prevents stimulation from causing reduction of EPSP amplitudes (Nguyen and Atwood, 1990). It is not yet known whether altered presynaptic Ca cur- 
rents underlie any of the aforementioned changes in synaptic strength.

It is also possible that depolarization is mimicking the actions of a growth factor. For example, both NGF and depolarization can have similar effects on c-fos expression (Sheng and Greenberg, 1990). Thus, it will be of interest to learn whether depolarization is mimicking the actions of a growth factor(s) that participates in regulation of developmental changes in specific currents such as those observed during ascidian development (Simoncini et al., 1988).

\section{References}

Armstrong DL (1989) Calcium channel regulation by calcineurin, a $\mathrm{Ca}^{2+}$-activated phosphatase in mammalian brain. Trends Neurosci 12:117-122.

Bean BP (1989a) Classes of calcium channels in vertebrate cells. Annu Rev Physiol 51:367-384.

Bean BP (1989b) Neurotransmitter inhibition of neuronal calcium currents by changes in channel voltage dependence. Nature 340:153156.

Belles B, Hescheler J, Trautwein W, Blomgren K, Karlsson JO (1988) A possible physiological role of the $\mathrm{Ca}$-dependent protease calpain and its inhibitor calpastatin on the Ca current in guinea pig myocytes. Pfluegers Arch 412:554-556.

Boland LM, Dingledine R (1990) Multiple components of both transient and sustained barium currents in a rat dorsal root ganglion cell line. J Physiol (Lond) 420:223-245.

Carafoli E (1987) Intracellular calcium homeostasis. Annu Rev Biochem 56:395-433.

Chad JE, Eckert R (1986) An enzymatic mechanism for calcium current inactivation in dialysed Helix neurones. J Physiol (Lond) 378: 31-51.

Collins F, Schmidt MF, Guthrie PB, Kater SB (1991) Sustained increase in intracellular calcium promotes neuronal survival. J Neurosci $11: 2582-2587$

Delorme EM, McGee R Jr (1986) Regulation of voltage-dependent $\mathrm{Ca}^{2+}$ channels of neuronal cells by chronic changes in membrane potential. Brain Res 397:189-192.

DeLorme EM, Rabe CS, McGee R Jr (1988) Regulation of the number of functional voltage-sensitive $\mathrm{Ca}^{++}$channels on $\mathrm{PC} 12$ cells by chronic changes in membrane potential. J Pharmacol Exp Ther 244:838-843.

DeRiemer SA, Strong JA, Albert KA, Greengard P, Kaczmarek LK (1985) Enhancement of calcium current in Aplysia neurones by phorbol ester and protein kinase C. Nature 313:313-316.

Dice JF (1987) Molecular determinants of protein half-lives in eukaryotic cells. FASEB J 1:349-357.

Dunlap K, Fischbach GD (1981) Neurotransmitters decrease the calcium conductance activated by depolarization of embryonic chick sensory neurones. J Physiol (Lond) 317:519-535.

Eckert R, Tillotson DL (1981) Calcium-mediated inactivation of the calcium conductance in caesium-loaded giant neurones of Aplysia californica. J Physiol (Lond) 314:265-280.

Ferrante J, Triggle DJ (1990) Homologous and heterologus regulation of voltage-dependent calcium channels. Biochem Pharmacol 39:12671270 .

Franklin JL, Willard AL (1988) Chronic depolarization reduces $\mathrm{Ca}^{2+}$ current density in cultured rat myenteric neurons. Soc Neurosci Abstr 14:645.

Franklin JL, Willard AL (1989) Inverse regulation of Ca current density and survival by depolarization of cultured rat myenteric neurons. Soc Neurosci Abstr 15:438.

Gallego R, Kuno M, Nunez R, Snider WD (1979) Disuse enhances synaptic efficacy in spinal motoneurones. J Physiol (Lond) 291:191205.

Garber SS, Hoshi T, Aldrich RW (1989) Regulation of ionic currents in pheochromocytoma cells by nerve growth factor and dexamethasone. J Neurosci 9:3976-3987.

Gross RA, MacDonald RL (1989) Cyclic AMP selectively reduces the $\mathrm{N}$-type calcium current component of mouse sensory neurons in culture by enhancing inactivation. J Neurophysiol 61:97-105.

Grynkiewicz G, Poenie M, Tsien RY (1985) A new generation of $\mathrm{Ca}^{2+}$ indicators with greatly improved fluorescence properties. J Biol Chem 260:3440-3450.
Gutnick MJ, Lux HD, Swandulla D, Zucker H (1989) Voltage-dependent and calcium-dependent inactivation of calcium channel current in identified snail neurones. J Physiol (Lond) 412:197-220.

Hamill OP, Marty A, Neher E, Sakmann B, Sigworth FJ (1981) Improved patch-clamp techniques for high-resolution current recording from cells and cell-free membrane patches. Pfluegers Arch 391:85100 .

Hinz I, Wernig A (1988) Prolonged nerve stimulation causes changes in transmitter release at the frog neuromuscular junction. J Physiol (Lond) 401:557-565.

Hirning LD, Fox AP, Miller RJ (1990) Inhibition of calcium currents in cultured myenteric neurons by NPY: evidence for direct receptor/ channel couling. Brain Res 532:120-130.

Kaczmarek LK, Levitan IB (1987) Neuromodulation. The biochemical control of neuronal excitability. New York: Oxford UP.

Lipscombe D, Kongsamut S, Tsien RW (1989) $\alpha$-Adrenergic inhibition of sympathetic neurotransmitter release mediated by modulation of N-type calcium-channel gating. Nature 340:639-642.

Melloni E, Pontremoli S (1989) The calpains. Trends Neurosci 12 : 438-444.

Morad M, Davies NW, Kaplan JH, Lux HD (1988) Inactivation and block of calcium channels by photo-released $\mathrm{Ca}^{2+}$ in dorsal root ganglion neurons. Science 241:842-844.

Nerbonne JM, Gurney AM (1989) Development of excitable membrane properties in mammalian sympathetic neurons. J Neurosci 9 : 3272-3286.

Nguyen PV, Atwood HL (1990) Expression of long-term adaptation of synaptic transmission requires a critical period of protein synthesis. J Neurosci 10:1099-1109.

Nishi R, Willard AL (1985) Neurons dissociated from rat myenteric plexus retain differentiated properties when grown in cell culture. I. Morphological properties and immunocytochemical localization of transmitter candidates. Neuroscience 16:187-199.

O'Dowd DK (1983) RNA synthesis dependence of action potential development in spinal cord neurones. Nature 303:619-621.

O'Dowd DK, Ribera AB, Spitzer NC (1988) Development of voltagedependent calcium, sodium, and potassium currents in Xenopus spinal neurons. J Neurosci 8:792-805.

Owen CS, Shuler RL (1989) Spectral evidence for non-calcium interactions of intracellular indo-1. Biochem Biophys Res Commun 163: 328-333.

Panza G, Grebb JA, Sanna E, Wright AG Jr, Hanbauer I (1985) Evidence for down-regulation of ${ }^{3} \mathrm{H}$-nitrendipine recognition sites in mouse brain after long-term treatment with nifedipine or verapamil. Neuropharmacology 24:1113-1117.

Rane SG, Dunlap K (1986) Kinase Cactivator 1,2-oleoylacetylglycero attenuates voltage-dependent calcium current in sensory neurons. Proc Natl Acad Sci USA 83:184-188.

Reich E, Goldberg IH (1964) Actinomycin and nucleic acid function. In: Progress in nucleic acid research and molecular biology (Davidson J, Cohn W, eds), pp 183-234. New York: Academic.

Ribera AB, Spitzer NC (1989) A critical period of transcription required for differentiation of the action potential of spinal neurons. Neuron 2:1055-1062.

Robbins N, Fischbach GD (1971) Effect of chronic disuse of rat soleus neuromuscular junctions on presynaptic function. J Neurophysiol 34: 570-578.

Scott RH, Dolphin AC (1989) G-protein regulation of neuronal voltage-activated calcium currents. Gen Pharmacol 20:715-720.

Sheng M, Greenberg ME (1990) The regulation of c-fos and other immediate early genes in the nervous system. Neuron 4:477-485.

Sibley DR, Benovic JL, Caron MG, Lefkowitz RJ (1987) Regulation of transmembrane signaling by receptor phosphorylation. Cell 48 : 913-922.

Simoncini L, Block ML, Moody WJ (1988) Lineage-specific development of calcium currents during embryogenesis. Science 242:15721575.

Skattebol A, Brown AM, Triggle DJ (1989) Homologous regulation of voltage-dependent calcium channels by 1,4-dihydropyridines. Biochem Biophys Res Commun 160:929-936.

Tamm I, Sehgal PB (1978) Halobenzimidazole ribosides and RNA synthesis of cells and viruses. Adv Virus Res 22:187-258.

Tsien RW, Lipscombe D, Madison DV, Bley KR, Fox AP (1988) Multiple types of neuronal calcium channels and their selective modulation. Trends Neurosci 11:431-437.

Wahl M, Lucherini MJ, Gruenstein E (1990) Intracellular $\mathrm{Ca}^{2+}$ mea- 
surement with Indo-1 in substrate-attached cells: advantages and special considerations. Cell Calcium 11:487-500.

Walicke PA, Campenot RB, Patterson PH (1977) Determination of transmitter function by neuronal activity. Proc Natl Acad Sci USA $74: 5767-5771$.

Wanke E, Ferroni A, Malgaroli A, Ambrosini A, Pozzan T, Meldolesi J (1987) Activation of a muscarinic receptor selectively inhibits a rapidly inactivated $\mathrm{Ca}^{2+}$ current in rat sympathetic neurons. Proc Natl Acad Sci USA 84:4313-4317.
Wettstein FO, Noll H, Penman S (1964) Effect of cycloheximide on ribosomal aggregates engaged in protein synthesis in vitro. Biochim Biophys Acta 87:525-528.

Willard AL (1990) A vasoactive intestinal peptide-like cotransmitter at cholinergic synapses between rat myenteric neurons in cell culture. J Neurosci 10:1025-1034.

Yaari Y, Hamon B, Lux HD (1987) Development of two types of calcium channels in cultured mammalian hippocampal neurons. Science 235:680-682. 